Special Issue of the 8th International Advances in Applied Physics and Materials Science Congress (APMAS 2018)

\title{
Sound Insulation Performance of Short Cotton Fibre Waste/Recycled Acrylonitrile Butadiene Styrene Composites
}

\author{
Y. CAN* \\ R\&D Center, Oyak Renault, Bursa, Turkey
}

\begin{abstract}
Recyclability is one of the key subjects in the automotive industry to reduce environmental pollution and economic aspects. Today, in an average passenger car, around 150-200 kg of polymer materials are used. One of the most used plastics in the vehicles is acrylonitrile butadiene styrene (ABS) polymer. In the presented study, a recycled ABS based sound insulation composite materials were developed by reinforcing with cotton fiber wastes. Recycled ABS (ABSr) is dissolved at room temperature with chemical solvents and mixed with different weight percentage $(10 \%, 20 \%, 30 \%)$ cotton fiber wastes. The mechanical properties, the sound insulation coefficient, and sound transmission coefficients of the developed materials were obtained. The developed materials were concluded according to cotton fiber waste weight percentages.
\end{abstract}

DOI: 10.12693/APhysPolA.135.772

PACS/topics: sound insulation, cotton fiber wastes, recycling, transmission loss, polymer composites

\section{Introduction}

As industrial wastes continue to accumulate, they are becoming a significant problem for the environment as well as for public health. Likewise, the decrease of natural resources is also becoming a problem. Focusing on efforts to obtain more environmentally respectful new products should be the starting point for environmental sustainability. Another important environmental problem is acoustic pollution, directly related to developed societies and causing their quality of life to diminish [1]. Noise control has been a challenge in many application fields. A growing number of standards limit human exposure to environmental noise in workplaces and homes, thus putting increasingly stringent limits to the noise produced by vehicles, machines, and household appliances. The conventional way to reduce unwanted noise is to use passive noise control strategies such as acoustic insulation, acoustic absorption, and noise source mitigation. In general lines, these strategies consist of adding porous or fibrous materials and rigid barriers in the acoustic path, between the noise source and the listener to cause reflection and/or dissipate part of the generated acoustic power [2]. Therefore, cotton or other fibre wastes have been studied to develop sound insulation panels by the researchers [3, 4].

In this study, three types of the cotton fiber wastes/ABSr (CFW/ABSr) composite materials have been developed to apply noise reduction panels. The sound transmission loss and sound absorption coefficients of the produced composites were measured and compared to each other.

*corresponding author; e-mail: yucel.can@renault.com

\section{Materials and methods}

A recycled automotive parts by ABS thermoplastics were collected and chopped as $1-3 \mathrm{~mm}$ sizes. CFWs were obtained from a cotton towel manufacturing company. The cotton fiber wastes originated from towel trimming. They contained 0.3 to $1 \mathrm{~mm}$ length cotton fibers. Figure $1 \mathrm{a}$ and $\mathrm{b}$ shows ABSr thermoplastic polymer granules and cotton wastes, respectively. Three types of specimens were performed to understand the effect of the $\mathrm{CFW}$ ratio in the $\mathrm{CFW} / \mathrm{ABSr}$ composites.

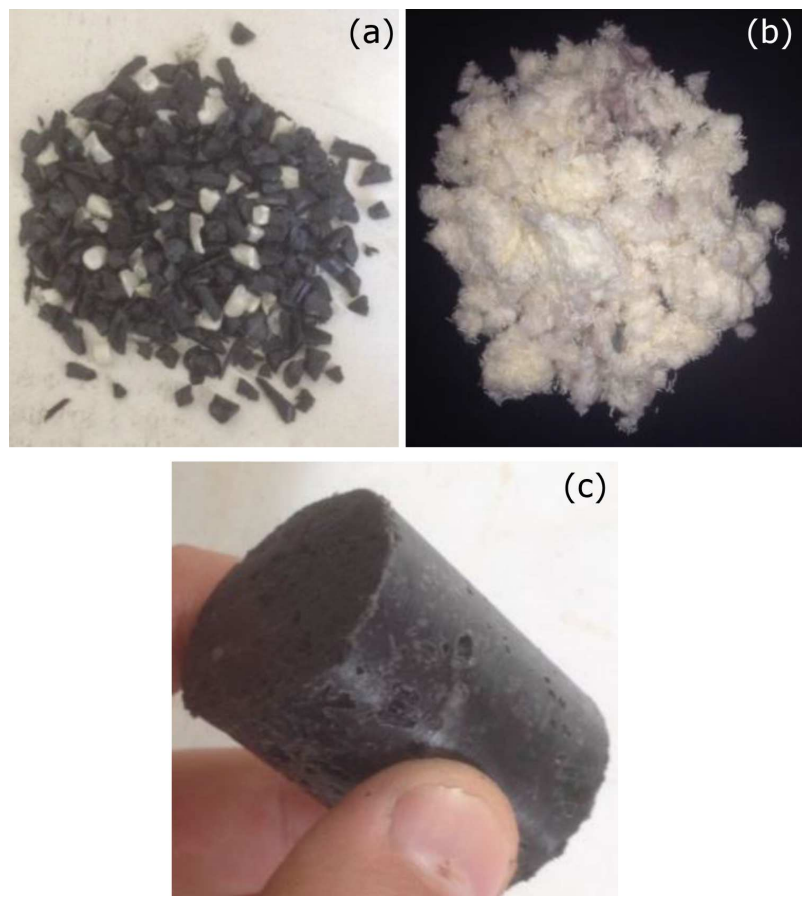

Fig. 1. (a) Obtained ABSr, (b) CFWs, (c) produced CFW/ABSr composite specimen. 
The CFWs were reinforced to ABSr matrix at 30, 20, and $10 \mathrm{wt} \%$. The ABSr matrix material was chemically dissolved by methyl ethyl ketone and mixed with totally dry CFWs at the given weight percent. The mixing was continued to obtain fully homogeneous composites. These mixtures were molded. The specimens were a cylindrical shape with dimensions $29 \mathrm{~mm}$ diameter and $43 \mathrm{~mm}$ height. A sample photo of the produced specimens is shown in Fig. 1c.

The experimental measurements were based on theoretical calculations. The transmission loss (TL) value was calculated using Eq. (1), from the measured sound power in the impedance tube

$$
T L=10 \log _{10}\left(\frac{W_{\text {src }}}{W_{\text {rec }}}\right),
$$

where $W_{\text {src }}$ is incident sound power, and $W_{\text {rec }}$ is the received sound power.

The sound absorption coefficients were also calculated using Eqs. (2) and (3):

$$
\alpha=1-|R|^{2}=1-R_{r}^{2}-R_{i}^{2},
$$

where $R=|R| \mathrm{e}^{\mathrm{j} \varphi R}=R_{r}+\mathrm{j} R_{i}$ and $\frac{z}{\rho c}=\frac{r}{\rho c}+\frac{\mathrm{j} x}{\rho c}=\frac{1+R}{1-R}$ is the normal specific acoustic impedance ratio, and $\rho=1.290\left(\frac{P}{101.325}\right)\left(\frac{273.15}{273.15+T}\right)$, where $\rho$ is air density $\left(\mathrm{gm} / \mathrm{cm}^{3}\right)$ and $P$ is atmospheric pressure $(\mathrm{kPa})$ and $T$ is the room temperature $\left({ }^{\circ} \mathrm{C}\right)$.

Estimation of $1 / 3$ octave and $1 / 1$ octave results in

$$
\alpha_{\text {band }}=\frac{1}{n} \sum_{i=1}^{n} \alpha_{f_{i}},
$$

where $\alpha_{\text {band }}$ is the absorption coefficient of the desired $1 / 3$ octave or $1 / 1$ octave band, $n$ is the number of bins in the band, $f_{i}$ is a frequency bin in the desired $1 / 3$ octave or $1 / 1$ octave to be estimated and $\alpha_{f_{i}}$ is the absorption measured by this test method in the indicated frequency bin.

All measurements were performed by using Testsens ${ }^{\circledR}$ impedance tube (Bias Co/Turkey). Experiments were performed according to ASTM 1050-12 [5].

\section{Results and discussion}

The sound TL measurements are given in Fig. $2 \mathrm{a}-\mathrm{c}$ for $10,20,30 \mathrm{wt} \%$ of CFW contents, respectively. These figures show variations of the TL values according to CFW weight percent. TL values are significant to understand a material sound isolation performance [6]. In these figures, TL values are presented at three CFW wt\% and the different frequency levels. In $10 \mathrm{wt} \%$, CFW/ABSr composite specimen shows almost linear TL behavior concerning frequency increasing. However, in the $20 \mathrm{wt} \%$ after $2000 \mathrm{~Hz}$ frequency and the $30 \mathrm{wt} \% \mathrm{CFW} / \mathrm{ABSr}$ composites after $1000 \mathrm{~Hz}$ frequency, the TL value reaches the highest mean value which is around $70 \mathrm{~dB}$. It is observed that increasing the weight percent of the CFW in the ABS polymer matrix improves the TL performance of the composites.
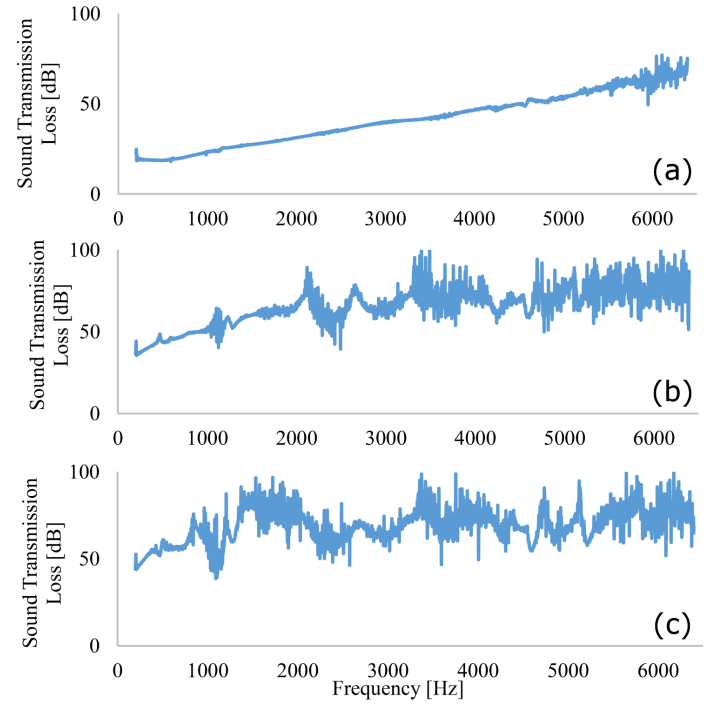

Fig. 2. Measured TL performance of the produced CFW/ABSr composites according to from low to highfrequency sound waves: (a) $10 \mathrm{wt} \%$, (b) $20 \mathrm{wt} \%$, (c) $30 \mathrm{wt} \% \mathrm{CFW} / \mathrm{ABSr}$ composite.

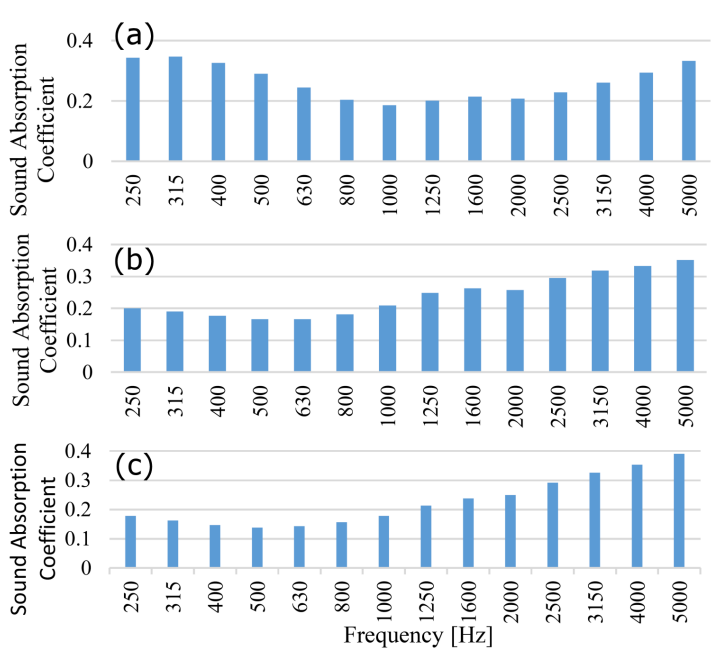

Fig. 3. Sound absorption coefficients of the produced CFW/ABSr composites: (a) $10 \mathrm{wt} \%$, (b) $20 \mathrm{wt} \%$, (c) $30 \mathrm{wt} \% \mathrm{CFW} / \mathrm{ABSr}$ composite.

Sound transmission loss property of the produced composites is very high. That means a layer by this material can block the sound waves and does not permit transmission through the section around $45 \mathrm{~dB}$ to $80 \mathrm{~dB}$. The produced composite is hard and solid. Therefore, sound absorption coefficients were found to be very low in enormous frequency levels. The measured sound absorption coefficient results were given in Fig. $3 \mathrm{a}-\mathrm{c}$ for 10, 20, $30 \mathrm{wt} \%$ of CFW contents, respectively. These figures show that, by increasing the $\mathrm{CFW}$ ratio in the $\mathrm{CFW} / \mathrm{ABSr}$ composites, the sound absorption coefficients decrease at low-frequency sound levels between 0 to $1000 \mathrm{~Hz}$, but beyond the $1000 \mathrm{~Hz}$ sound level, increase of the CFW ratio improves the sound absorption coefficient. 


\section{Conclusion}

In this study, CFW/ABSr composites were developed to apply as noise insulation panels. Obtained composites show very high-level sound transmission loss and deficient sound absorption properties. CFW weight percent ratio reduced the sound absorption coefficient up to $1000 \mathrm{~Hz}$ and increased the sound absorption coefficient after this frequency. In low CFW reinforcement, the TL value of the composite was found to be an almost linear function of the frequency. However, in higher CFW incorporation changed the TL variation after a certain value from a linear function of the frequency to a constant mean value.

\section{References}

[1] M. Garcia-Valles, G. Avila, S. Martinez, R. Terradas, J.M. Nogués, Chemosphere 72, 1098 (2008).

[2] D.A. Siviero, J.R.D.F. Arruda, Appl. Acoust. 73, 1013 (2012).
[3] A. Patnaik, M. Mvubu, S. Muniyasamy, A. Botha, R.D. Anandjiwala, Energy Build. 92161 (2015).

[4] H. Binici, O. Aksogan, J. Mater. Cycles Waste Manage. 17, 157 (2015).

[5] ASTM E50-12 Standard, Standard Test Method for Impedance and Absorption of Acoustical Materials Using a Tube, Two Microphones, and a Digital Frequency Analysis System.

[6] J.A. Moore, R.H. Lyon, J. Acoust. Soc. Am. 89, 777 (1991). 